\title{
CAMA
}

Centre for Applied Macroeconomic Analysis

\section{Increasing Trends in the Excess Comovement of Commodity Prices}

\section{CAMA Working Paper 9/2016 February 2016}

Kazuhiko Ohashi

Graduate School of International Corporate Strategy (ICS), Hitotsubashi University

\section{Tatsuyoshi Okimoto}

Crawford School of Public Policy, ANU and

Centre for Applied Macroeconomic Analysis, ANU

\section{Abstract}

We investigate how the excess comovement of commodity prices, that is, the correlation in commodity returns after filtering out common fundamental shocks, has changed over the past three decades by developing the smooth-transition dynamic conditional correlation model that can capture long-run trends and short-run dynamics of correlation simultaneously. Using data from 1983 to 2011, we find that significant increasing longrun trends in excess comovement have appeared since around 2000 . We confirm that these increasing trends are neither an artifact of the financial crisis after the bankruptcy of Lehman Brothers in September 2008 nor the time-varying sensitivities of commodity returns to common fundamental shocks. Moreover, we find that no significant increasing trends exist in the excess comovement among off-index commodities and that the surge of global demand alone cannot explain the increasing trends. These findings provide additional evidence for the timing and scope of the recent increasing commodity-return correlations that suggest the influence of the financialization of commodity markets starting around 2000. 


\section{Keywords}

excess comovement, commodity return, time-varying correlation, smooth transition, regime change, financialization

\section{JEL Classification}

C32, C51, G15

Address for correspondence:

(E) cama.admin@anu.edu.au

ISSN 2206-0332

The Centre for Applied Macroeconomic Analysis in the Crawford School of Public Policy has been established to build strong links between professional macroeconomists. It provides a forum for quality macroeconomic research and discussion of policy issues between academia, government and the private sector.

The Crawford School of Public Policy is the Australian National University's public policy school, serving and influencing Australia, Asia and the Pacific through advanced policy research, graduate and executive education, and policy impact. 


\title{
Increasing Trends in the Excess Comovement of Commodity Prices
}

\author{
Kazuhiko Ohashi*
}

Tatsuyoshi Okimoto ${ }^{\dagger}$

\begin{abstract}
We investigate how the excess comovement of commodity prices, that is, the correlation in commodity returns after filtering out common fundamental shocks, has changed over the past three decades by developing the smooth-transition dynamic conditional correlation model that can capture long-run trends and short-run dynamics of correlation simultaneously. Using data from 1983 to 2011, we find that significant increasing long-run trends in excess comovement have appeared since around 2000. We confirm that these increasing trends are neither an artifact of the financial crisis after the bankruptcy of Lehman Brothers in September 2008 nor the time-varying sensitivities of commodity returns to common fundamental shocks. Moreover, we find that no significant increasing trends exist in the excess comovement among off-index commodities and that the surge of global demand alone cannot explain the increasing trends. These findings provide additional evidence for the timing and scope of the recent increasing commodity-return correlations that suggest the influence of the financialization of commodity markets starting around 2000.
\end{abstract}

JEL classification: C32, C51, G15

Key Words: excess comovement; commodity return; time-varying correlation; smooth transition; regime change; financialization

${ }^{*}$ Professor, Graduate School of International Corporate Strategy (ICS), Hitotsubashi University, 2-1-2 Hitotsubashi, Chiyoda-ku, Tokyo 101-8439, JAPAN. Phone: +81-3-4212-3102. Fax: +81-3-4212-3020. E-mail: kohashi@ics.hit-u.ac.jp.

${ }^{\dagger}$ Corresponding author, Associate Professor, Crawford School of Public Policy, Australian National University, 132 Lennox Crossing, ANU, Acton, ACT 2601, AUSTRALIA. Phone: +61-2-6125-4763. Fax: +61-2-6125-8448. E-mail: tatsuyoshi.okimoto@anu.edu.au. 


\section{Introduction}

Since the early 2000s, commodities have emerged as an additional asset class alongside traditional ones such as stocks and bonds. Many researchers, using data from before the 2000s, have found slightly negative return correlations between commodity and stock returns (Greer [16]; Gorton and Rouwenhorst [15]). Return correlations among commodities in different sectors have also been found to be small (Erb and Harvey [13]). Moreover, several papers have reported decreasing or non-increasing trends of return correlations between commodities and stocks at least before the financial crisis after the bankruptcy of Lehman Brothers in September 2008 (Chong and Miffre, [9]; Büyükşahin, Haigh, and Robe, [5]).

These characteristics of commodity returns implied an opportunity for diversification and thus have attracted investors worldwide. Institutional investors and hedge funds have started intensively trading commodity indices such as Standard \& Poor's Goldman Sachs Commodity Index (S\&P-GSCI) and the Dow-Jones UBS Commodity Index (DJUBS). Such commodity index investment, however, has changed the environments. In particular, with a massive inflow of funds into commodity markets by financial institutions starting around 2000, which is referred to as financialization, ${ }^{1}$ the commodity markets seem to have become more integrated into traditional markets and among themselves. For instance, Silvennoinen and Thorp [26] show that return correlations between commodities and stocks (or bonds) have increased well before the 2008 financial crisis, while Tang and Xiong [28] find significant increasing trends in the return correlations between crude oil and other commodities since 2004. As a result, analyzing time-varying correlations in commodity markets has become an important issue.

In this paper, we investigate whether and how correlations among commodity returns have changed over the last three decades possibly due to the financialization of commodity markets starting around 2000. We address these questions, however, from a slightly different viewpoint. We focus on excess comovement in commodity returns, initially raised by Pindyck and Rotemberg [23] and extended by Deb, Trivedi, and Varangis [10]. The excess comovement of commodities is defined as the correlation among commodity returns after filtering out the common macroeconomic factors and hence is interpreted as comovement unrelated to market fundamentals. We investigate how such excess comovement has changed over time.

The test of excess comovement among commodity returns is originally conducted by Pindyck and Rotemberg [23]. For monthly data from 1960 to 1985, they find that the excess comovements among several commodity returns are significant. Deb, Trivedi, and Varangis [10] extend the

\footnotetext{
${ }^{1}$ For a survey regarding the financialization of commodity markets, see Cheng and Xiong [8].
} 
model by introducing conditional heteroskedasticity and a time-varying conditional correlation with multivariate GARCH processes. The time-varying conditional correlation model allows them to analyze the short-run time-varying fluctuation in excess comovement, but the long-run mean of the correlation is set to be constant. Using monthly data from 1974 to 1992, they find that evidence of excess comovement becomes weaker especially when the multivariate GARCH is applied.

In this paper, we develop the smooth-transition dynamic conditional correlation (STDCC) model based on the smooth-transition correlation (STC) model by Berben and Jansen [4] and Kumar and Okimoto [19], and the dynamic conditional correlation (DCC) model by Engle [11] to generalize the aforementioned models. In the STDCC model with time as a transition variable, the STC part describes long-run trends in correlation and the DCC part captures short-run fluctuation. Thus, combining them enables us to investigate changes in long-run trends and short-run dynamics of excess comovement simultaneously. Moreover, the STC part allows us to detect solely from the data when and how a regime change, if any, in excess comovement occurs. To best of our knowledge, this paper is the first to develop the STDCC model and apply it to examine the timing of the regime change in the excess comovement of commodity returns.

The main contribution of this paper is that using this STDCC model for monthly data from 1983 to 2011, we find several new empirical facts regarding the behavior of excess comovement among commodities. First, the STDCC model detects significant long-run increasing trends in commodity excess comovement. Moreover, in contrast with the time-varying conditional correlation model by Deb, Trivedi, and Varangis [10] that cannot detect long-run trends, this paper finds the importance of long-run increasing trends in the excess comovement of commodity prices relative to short-run conditional correlation dynamics. Indeed, our results indicate that the STC model that captures long-run trends is sufficient for characterizing the dynamics of excess comovement among commodities from 1983 to 2011.

Second, both STC and STDCC models find that such long-run increasing trends in excess comovement among commodities have appeared since around 2000. Until 2000, the excess comovement of commodity prices was almost constant and remained at low levels, which is fairly consistent with Deb, Trivedi, and Varangis [10]. However, it has increased gradually since 2000 and reached much higher levels toward 2011. This result is generally consistent with the theoretical prediction of Basak and Pavlova [3] that the presence of index investment in commodities, which became popular around 2000, increases correlation among commodity returns. This result also complements Tang and Xiong [28], who find increasing trends in correlations between crude oil and non-energy commodities since (exogenously chosen) 2004, and Silvennoinen and Thorp [26], who detect a regime change in the increasing correlations between commodities and stocks (or 
bonds) since around 2000, although both sets of researchers analyze return correlations, not excess comovement. ${ }^{2}$ Furthermore, this result is closely related to Le Pen and Sev́i [20], who find a small increase of excess comovement among commodities between 2000 and 2004 and a large increase after 2008, based on the rolling window analysis.

Third, we examine the possibility that the excess comovement among commodities might decrease after the 2008 financial crisis and find that the financial crisis after the bankruptcy of Lehman Brothers in September 2008 alone cannot explain the increasing trends in excess comovement among commodities. For this test, we extend the two-state STC model to the three-state model and investigate whether and when, if any, there are decreasing trends in excess comovement. The results indicate that the increasing trends in excess comovement after 2000 are the dominant feature of the dynamics in commodity excess comovement. This is consistent with Adams and Glück [1] who show that the 2008 financial crisis alone cannot explain the size and persistence of comovement. This also complements the findings of increasing trends in correlations by Tang and Xiong [28], who investigate only monotonic trends, and Silvennoinen and Thorp [26], who examine possible non-monotonic trends, but use the data up to 2009.

Fourth, we show that the increasing long-run trends of excess comovement are robust regarding changes in the sensitivities of commodity returns to common macroeconomic factors. Since the STC model assumes that the sensitivities of commodity returns to common macroeconomic factors are constant, there remains a possibility that the increasing trends in excess comovement might be caused by the (ignored) increasing trends in sensitivities to common macroeconomic factors. We examine the model that incorporates such a possibility and obtain qualitatively the same result.

Fifth, we find that, unlike the results above, there are no significant increasing trends in excess comovement among off-index commodities. ${ }^{3}$ This is consistent with the theoretical result by Basak and Pavlova [3] who show that, in the presence of index investment in commodities, correlation among indexed commodities becomes higher than that among off-index ones. This result is also generally consistent with Tang and Xiong [28], who find a larger increase in correlations for indexed commodities than for off-index commodities.

Finally, we show that our results are robust regarding global macroeconomic shocks. We examine the STC model taking account of the global macroeconomic variables, instead of the U.S. macroeconomic variables, and still find significant, though a bit weaker, long-run increasing trends in commodity excess comovement. Thus, the increasing trends of excess comovement are

\footnotetext{
${ }^{2}$ Silvennoinen and Thorp [26] apply the double smooth transition conditional correlation GARCH (DSTCCGARCH) model, which is closely related to the STDCC model in this paper.

${ }^{3}$ Following Tang and Xiong [28], we call those commodities listed in either the S\&P-GSCI or DJUBS indexed commodities and those commodities listed in neither off-index commodities.
} 
not entirely attributed to the recent growth of the world economy.

This paper is organized as follows. Section 2 reviews the related literature, while Section 3 provides a review of the model and explains the estimation method. Section 4 conducts the empirical analysis. Last, Section 5 serves as a conclusion.

\section{Review of Related Literature}

In this paper, we investigate whether and how the excess comovement of commodity prices has changed over the last three decades possibly due to the financialization of commodity markets starting around 2000. In this section, we briefly review the previous studies about the financialization of commodity markets and excess comovement of commodity prices.

In the past decade, a sharp increase in the popularity of commodity investing generated a huge capital inflow into commodity futures. ${ }^{4}$ While prices of commodities continued to rise, their volatilities also increased sharply. Such high volatilities generated concern about and interest in whether and how financialization of commodities has affected commodity prices.

While several early works, such as Stoll and Whaley [27] and Irwin and Sanders [18], show few effects of financialization, as already mentioned, Tang and Xiong [26] find that the return correlations between crude oil and non-energy commodities have increasing trends since 2004 and that these increasing trends among the indexed commodities are significantly larger than those among the off-index commodities. They suggest that these results are caused by the financialization of commodity markets. Moreover, Silvennoinen and Thorp [26] show that the return correlations between commodities and stocks (or bonds) have increased since 2000 and suggest that this is due to integration between the markets of commodities and traditional assets through capital flows into commodity markets.

To complement the suggestions by Tang and Xiong [28] and Silvennoinen and Thorp [26], several researchers have started studying the cause of increasing return correlations in more detail. Using the data of individual trader positions in the U.S. futures markets, Büyükşahin and Robe [6] show that the return correlations between commodities and stocks increase due to greater participation by speculators, especially hedge funds. Similarly, Le Pen and Sev́i [20] find that the measures of traders' hedging and speculative activities calculated from the CFTC data have significant explanatory power concerning the excess comovement among commodities. Furthermore, applying the factor-augmented VEC model to common factors extracted from commodity prices, the total open interest of commodity futures (a proxy for the financialization of commodity markets), and

\footnotetext{
${ }^{4}$ CFTC estimated the inflow of funds to commodity futures indexes amounted about $\$ 200$ billion from 2000 to 2008. See also Cheng and Xiong [8].
} 
several macroeconomic variables, Pradhananga [24] shows that open interest significantly affects other variables and that financialization of commodity markets causes the rise in the comovement of unrelated commodity prices.

Finally, Basak and Pavlova [3] develop a theoretical model to analyze the effect of financialization. They provide theoretical results that support the empirical findings and show, among other things, that financialization leads to an increase in correlations among commodities and/or between commodities and stocks.

Another important studies related this paper deal with the excess comovement of commodity prices. Pindyck and Rotemberg [23] theoretically demonstrate that the prices of unrelated commodities should move together exclusively in response to market participants' changing perceptions of the macroeconomic environment based on the standard competitive commodity price model. Nonetheless they empirically find a (weak) positive correlation among several commodity prices even after controlling the common macroeconomic factors and call it the excess comovement of commodity prices. Since then, several authors have pointed out that the excess comovement by Pindyck and Rotemberg [23] is sensitive to the choice of methodology and common factors. For example, Deb, Trivedi, and Varangis [10] show that evidence of excess comovement becomes weaker based on a multivariate GARCH model with a time-varying conditional correlation. Similarly, while Palaskas and Varangis [22] reject the presence of the excess comovement of commodity prices with a cointegration test, Cashin, McDermott, and Scott [7] show that excess comovement disappears when a different measure, concordance, is applied. Additionally, Ai, Chatrath, and Song [2] find little evidence of excess comovement once they include supply factors based on inventory and harvest data to control common macroeconomic factors.

In this paper, we nonetheless utilize excess comovement because we would like to investigate whether and how residual commodity-return correlation, unexplained by the selected common factors, change over time. If there is no change in the economic structure, we would expect no change in such residual return correlation i.e., excess comovement. If there is some change, there would be a change in excess comovement. For example, Le Pen and Sev́i [20] investigate changes of excess comovement with the rolling correlation method and find that there are small increases of excess comovement among commodities between 2000 and 2004 and large increases after 2008. In a similar vein, what we would like to do in this paper is to identify the timing and speed of such a change over the last three decades based on the STDCC model, providing a clue to the cause of change. It might be inventory, harvest, or a flow of funds into commodity markets. Searching for such a cause more rigorously is beyond the scope of this paper, but is an important next step. 


\section{Model and Estimation}

\subsection{Model}

The main purpose of this paper is to investigate whether and how the excess comovement of commodity prices, documented in Pindyck and Rotemberg [23] and doubted by Deb, Trivedi, and Varangis [10], has changed over the past three decades. In particular, we examine the long-run trends and short-run dynamics of excess comovement of commodity prices to capture the effect of the financialization of commodities through index investment starting around 2000. To this end, we investigate the following four models: the benchmark model with constant correlation, the DCC model with time-varying conditional correlation, the STC model with smoothly changing stationary level of correlation, and the STDCC model with time-varying conditional correlation around smoothly changing stationary level of correlation.

\subsubsection{Benchmark model}

Our benchmark model is the one used by Pindyck and Rotemberg [22] and given by the following equation:

$$
\Delta p_{i t}=\sum_{k=0}^{K} \alpha_{i k} \Delta x_{t-k}+\rho_{i} \Delta p_{i, t-1}+u_{i t}, i=1, \ldots, M, t=1, \ldots, T .
$$

Here, $\Delta$ is the difference operator and $p_{i}$ is the logarithm of the price of the $i$ th commodity. Hence, the explained variable of regression (1) is a commodity return. In addition, $x$ is a common set of macroeconomic variables to filter out the linear influence of macroeconomic shocks. The macroeconomic variables are logarithms of the CPI, industrial production, exchange rate, stock price index, money stock, and interest rate (not in logs). $\alpha_{i k}$ is a vector of coefficients of macroeconomic variables with lag $k$ for commodity $i$.

Pindyck and Rotemberg [23] theoretically demonstrate that the prices of unrelated commodities should move together exclusively in response to market participants' changing perceptions of the macroeconomic environment based on the standard competitive commodity price model. Mathematically, this implies that the $u_{i t}$ 's should be uncorrelated across commodities under the standard competitive commodity price model. Nonetheless they empirically find a (weak) positive correlation in the error term $u_{i}$ of the equation (1) from several commodities and call it excess comovement of commodity prices. ${ }^{5}$

\footnotetext{
${ }^{5}$ In this paper, we employ the same definition of excess comovement commodity prices as Pindyck and Rotemberg [23]. However, the definition of excess comovement depends on the controlled macroeconomic variables. Therefore, precisely speaking, our definition of excess comovement here is the comovement that cannot be explained by inflation, industrial production, exchange rate, stock price, money stock, and interest rate.
} 


\subsubsection{DCC model}

Deb, Trivedi, and Varangis [10] extend the benchmark model (1) by accommodating the conditional heteroskedasticity and time-varying conditional correlation based on the BEKK model developed by Engle and Kroner [12]. Following a similar idea, we use the DCC model proposed by Engle [11] as a time-varying conditional correlation model. To be more specific, let $\mathbf{u}_{t}=\left(u_{1 t}, \ldots, u_{M t}\right)^{\prime}=$ $\mathbf{H}_{t}^{1 / 2} \mathbf{v}_{t}$, where $\mathbf{H}_{t}$ is the $M \times M$ conditional covariance matrix at time $t$ of the commodity returns and $\mathbf{v}_{t}$ is assumed to be independently identically normally distributed with mean $\mathbf{0}$ and covariance matrix $\mathbf{I}_{M}, M \times M$ identity matrix. In the DCC model, $\mathbf{H}_{t}$ is decomposed as $\mathbf{H}_{t}=\mathbf{D}_{t} \mathbf{R}_{t} \mathbf{D}_{t}$, where $\mathbf{D}_{t}=\operatorname{diag}\left(h_{11, t}, \ldots, h_{n n, t}\right)^{1 / 2}, h_{i i, t}$ is the $(i, i)$ element of $\mathbf{H}_{t}$, and $\mathbf{R}_{t}$ is the time-varying conditional correlation. We assume that $h_{i i, t}$ follows the GARCH(1,1) model as

$$
h_{i i, t}=\omega_{i}+\beta_{i} h_{i i, t-1}+\alpha_{i} u_{i, t-1}^{2} .
$$

Following Engle [11], we model $\mathbf{R}_{t}$ as

$$
\left\{\begin{array}{l}
\mathbf{R}_{t}=\operatorname{diag}\left(q_{11, t}, \ldots, q_{M M, t}\right)^{-1 / 2} \mathbf{Q}_{t} \operatorname{diag}\left(q_{11, t}, \ldots, q_{M M, t}\right)^{-1 / 2} \\
\mathbf{Q}_{t}=(1-a-b) \overline{\mathbf{Q}}+b \mathbf{Q}_{t-1}+a \boldsymbol{\varepsilon}_{t-1} \boldsymbol{\varepsilon}_{t-1}^{\prime}
\end{array},\right.
$$

where $\boldsymbol{\varepsilon}_{t}=\mathbf{D}_{t}^{-1} \mathbf{u}_{t}$ is a standardized disturbance vector and $q_{i i, t}$ is the $(i, i)$ element of $\mathbf{Q}_{t}$. We can test the excess comovement between commodities $i$ and $j$ by testing $\bar{q}_{i j}=0$, where $\bar{q}_{i j}$ is the $(i, j)$ element of $\overline{\mathbf{Q}}$, since $\overline{\mathbf{Q}}$ is the unconditional correlation matrix of the standardized disturbance $\boldsymbol{\varepsilon}_{t}$.

\subsubsection{STC model}

One restriction of the DCC model is that the unconditional correlation, or the stationary level of correlation, is constant, although the conditional correlation is assumed to be time-varying. However, a large change of market environments such as rapid growth of commodity index investment might affect the stationary level of correlation. Hence, the assumption of the constant stationary level of correlation might not be appropriate.

To examine this possibility, we consider the smooth-transition correlation (STC) model as the third model. The smooth transition model is developed by Teräsvirta [29] in the AR model framework, and later used to model correlation dynamics by, among others, Berben and Jansen [4] and Kumar and Okimoto [19]. ${ }^{6}$ In the STC model, the time-varying correlation $\mathbf{R}_{t}$ is modeled as

$$
\mathbf{R}_{t}=\left(1-G\left(s_{t} ; c, \gamma\right)\right) \mathbf{R}^{(1)}+G\left(s_{t} ; c, \gamma\right) \mathbf{R}^{(2)},
$$

where $G$ is a logistic transition function given by

$$
G\left(s_{t} ; c, \gamma\right)=\frac{1}{1+\exp \left(-\gamma\left(s_{t}-c\right)\right)}, \quad \gamma>0
$$

\footnotetext{
${ }^{6}$ See also Silvennoinen and Teräsvirta [25] for more details of STC model.
} 
Here, $s_{t}$ is a transition variable governing the transition, $c$ is a location parameter determining the center of transition, and $\gamma$ is a smoothness parameter specifying the speed of transition. We use a time trend as a transition variable, namely $s_{t}=t / T$, to capture a long-run trends in unconditional correlation following Lin and Teräsvirta [21]. In addition, we assume $0.01 \leq c \leq 0.99$ so that we can detect the correlation transition within the sample period. In this framework, the time-varying correlation $\mathbf{R}_{t}$ changes smoothly and monotonically from $\mathbf{R}^{(1)}$ to $\mathbf{R}^{(2)}$ with time. Thus, we can interpret $\mathbf{R}^{(1)}$ as a stationary level of correlation around the beginning of the sample and $\mathbf{R}^{(2)}$ as a stationary level of correlation around the end of the sample. ${ }^{7}$

One of the main attractions of the STC model is that it can detect from the data when and how structural change, if any, in correlation occurs. In addition, the STC model can describe a wide variety of patterns of change in correlation, depending on parameters $c$ and $\gamma$, which can be estimated from the data. Thus, by estimating the STC model, we can estimate the best pattern of long-run trends in correlation. Furthermore, we can test the excess comovement in regime $k$ between commodities $i$ and $j$ by testing $r_{i j}^{(k)}=0$, where $r_{i j}^{(k)}$ is the $(i, j)$ element of $\mathbf{R}^{(k)}$. In addition, we can test the equality of excess comovement across regimes by testing $r_{i j}^{(1)}=r_{i j}^{(2)}$. This hypothesis test is particularly interesting when investigating the increase in excess comovement possibly caused by the development of index investment.

\subsubsection{STDCC model}

Our final model is the smooth-transition dynamic conditional correlation (STDCC) model, which is a combination of the DCC and STC models and given by

$$
\left\{\begin{array}{l}
\mathbf{R}_{t}=\operatorname{diag}\left(q_{11, t}, \ldots, q_{M M, t}\right)^{-1 / 2} \mathbf{Q}_{t} \operatorname{diag}\left(q_{11, t}, \ldots, q_{M M, t}\right)^{-1 / 2} \\
\mathbf{Q}_{t}=(1-a-b) \overline{\mathbf{Q}}_{t}+b \mathbf{Q}_{t-1}+a \boldsymbol{\varepsilon}_{t-1} \boldsymbol{\varepsilon}_{t-1}^{\prime} \\
\overline{\mathbf{Q}}_{t}=\left(1-G\left(s_{t} ; \gamma, c\right)\right) \overline{\mathbf{Q}}^{(1)}+G\left(s_{t} ; \gamma, c\right) \overline{\mathbf{Q}}^{(2)}
\end{array}\right.
$$

where $G$ is a logistic transition function (5). As we explained above, the DCC model is useful to describe the short-run behavior of conditional correlation, while the STC model can capture the long-run trends on the stationary level of correlation. Therefore, the STDCC model is expected to shed light on both short- and long-run dynamics of excess comovement of commodity prices. In the STDCC model, we can test the excess comovement in regime $k$ between commodity $i$ and $j$ by testing $\bar{q}_{i j}^{(k)}=0$, where $\bar{q}_{i j}^{(k)}$ is the $(i, j)$ element of $\overline{\mathbf{Q}}^{(k)}$, like in the STC model, but with taking the time-varying conditional correlation into consideration. Similarly, we can test the equality of excess comovement across regimes by testing $\bar{q}_{i j}^{(1)}=\bar{q}_{i j}^{(2)}$ under the dynamic conditional correlation.

\footnotetext{
${ }^{7}$ This formulation enables us to detect only a monotone change of correlation from $\mathbf{R}^{(1)}$ to $\mathbf{R}^{(2)}$. In subsection 3.4 , to investigate the possibility of non-monotonic change, we extend the model to have three states of correlation $\mathbf{R}^{(1)}, \mathbf{R}^{(2)}$, and $\mathbf{R}^{(3)}$. We then estimate the model and find that there is no significant difference between the results of two-state model and those of three-state model.
} 


\subsection{Estimation}

We estimate all models based on the maximum likelihood estimation (MLE), which is a standard method to estimate the benchmark regression model, the DCC model, and STC model. It is also straightforward to estimate the STDCC model via the MLE. One concern associated with the MLE, however, is that there may be too many parameters to be estimated. To mitigate the problem, we adopt the two-step approach proposed by Engle [11] to maximize the likelihood function.

Let $\theta$ be a vector of parameters to be estimated. Assuming $\mathbf{v}_{t}$ follows multivariate standard normal distribution independently, we can write the log likelihood function, $\mathcal{L}(\boldsymbol{\theta})$, of our model as

$$
\mathcal{L}(\boldsymbol{\theta})=-\frac{1}{2} \sum_{t=1}^{T}\left(M \log (2 \pi)+\log \left|\mathbf{H}_{t}\right|+\mathbf{u}_{t}^{\prime} \mathbf{H}_{t}^{-1} \mathbf{u}_{t}\right)
$$

Noting that $\mathbf{H}_{t}=\mathbf{D}_{t} \mathbf{R}_{t} \mathbf{D}_{t}$ and $\boldsymbol{\varepsilon}_{t}=\mathbf{D}_{t}^{-1} \mathbf{u}_{t}$, we can rewrite $(7)$ as

$$
\begin{aligned}
\mathcal{L}(\boldsymbol{\theta}) & =-\frac{1}{2} \sum_{t=1}^{T}\left(M \log (2 \pi)+\log \left|\mathbf{D}_{t} \mathbf{R}_{t} \mathbf{D}_{t}\right|+\mathbf{u}_{t}^{\prime} \mathbf{D}_{t}^{-1} \mathbf{R}_{t}^{-1} \mathbf{D}_{t}^{-1} \mathbf{u}_{t}\right) \\
& =-\frac{1}{2} \sum_{t=1}^{T}\left(M \log (2 \pi)+2 \log \left|\mathbf{D}_{t}\right|+\mathbf{D}_{t}^{-1} \mathbf{u}_{t}^{\prime} \mathbf{u}_{t} \mathbf{D}_{t}^{-1}+\log \left|\mathbf{R}_{t}\right|+\boldsymbol{\varepsilon}_{t}^{\prime} \mathbf{R}_{t}^{-1} \boldsymbol{\varepsilon}_{t}-\boldsymbol{\varepsilon}_{t}^{\prime} \boldsymbol{\varepsilon}_{t}\right) \\
& =\mathcal{L}_{m}\left(\boldsymbol{\theta}_{m}\right)+\mathcal{L}_{c}\left(\boldsymbol{\theta}_{m}, \boldsymbol{\theta}_{c}\right),
\end{aligned}
$$

where $\boldsymbol{\theta}_{m}$ and $\boldsymbol{\theta}_{c}$ are the parameters of marginal distribution and correlation, respectively, and

$$
\begin{aligned}
\mathcal{L}_{m}\left(\boldsymbol{\theta}_{m}\right) & =-\frac{1}{2} \sum_{t=1}^{T}\left(M \log (2 \pi)+2 \log \left|\mathbf{D}_{t}\right|+\mathbf{D}_{t}^{-1} \mathbf{u}_{t}^{\prime} \mathbf{u}_{t} \mathbf{D}_{t}^{-1}\right) \\
\mathcal{L}_{c}\left(\boldsymbol{\theta}_{m}, \boldsymbol{\theta}_{c}\right) & =-\frac{1}{2} \sum_{t=1}^{T}\left(\log \left|\mathbf{R}_{t}\right|+\boldsymbol{\varepsilon}_{t}^{\prime} \mathbf{R}_{t}^{-1} \boldsymbol{\varepsilon}_{t}-\boldsymbol{\varepsilon}_{t}^{\prime} \boldsymbol{\varepsilon}_{t}\right)
\end{aligned}
$$

Thus, the log likelihood function can be decomposed into two parts. The first part is related only with the parameters of marginal distribution and can be maximized by separately maximizing marginal likelihood for each commodity return. The second part of the likelihood is associated with the correlation dynamics, which can be used to estimate correlation parameters.

The two-step approach to estimate all parameters is to find

$$
\hat{\boldsymbol{\theta}}_{m}=\arg \max \mathcal{L}_{m}\left(\boldsymbol{\theta}_{m}\right)
$$

and then take this value as given in the second stage to get

$$
\hat{\boldsymbol{\theta}}_{c}=\arg \max \mathcal{L}_{c}\left(\hat{\boldsymbol{\theta}}_{m}, \boldsymbol{\theta}_{c}\right) .
$$

This two step estimation is consistent and asymptotically normal under reasonable regularity conditions. Although the formula to calculate the standard error of the correlation parameters is 
given in Engle [11], it might be too complicated to calculate it accurately, when the number of parameters is large, which is so in this paper. For this reason, we ignore the effect of the first-step estimation and use the usual MLE formula to evaluate the standard errors, which should not be a serious problem if the sample size is large.

\section{Empirical Results}

Our empirical analysis is based on monthly data with the sample period lasting from 1983:1 to 2011:7. For commodity prices, we obtain the indices of primary commodity prices published by the International Monetary Fund (IMF). Specifically, we use agricultural raw material (AGR), beverage (BEV), and metal (MET) indices. ${ }^{8}$ We exclude food and energy indices from our analysis, since they are available only from 1991 and 1992, respectively. Instead, we adopt the average oil prices (OIL), which is the average prices of U.K. Brent, Dubai, and West Texas Intermediate. In addition, we obtain the same US macroeconomic variables as those used by Pindyck and Rotemberg [23] from the Federal Reserve Economic Data (FRED) to filter out the influence of common macroeconomic shocks. These data include the seasonally adjusted consumer price index (CPI, $\Pi)$, the seasonally adjusted industrial production $(Y)$, the 3-month Treasury bill rate $(R)$, the trade weighted exchange rate index $(E)$, the seasonally adjusted money supply, M1 $(M)$, and the S\&P 500 stock price index $(S) .^{9}$

\subsection{Weak evidence of the excess comovement of commodity prices}

We estimate the benchmark model (1) with $K=1$ as Pindyck and Rotemberg [23]. ${ }^{10}$ Our estimation results are given in Table 1 . As can be seen, CPI, industrial production, and exchange rate are significant at least at the $10 \%$ level for AGR, while the interest rate and the exchange rate have some explanatory power on BEV. More macroeconomic variables are important for the two other commodities. Specifically, all variables but money supply are significant for MET, whereas all variables but stock price are significant for OIL. In addition, the lagged dependent variable $(A R 1)$ is significant for all commodities. Overall, the explanatory power of the macroeconomic variables and the lagged dependent variable is relatively high with $R^{2}$ ranging from $0.142(\mathrm{BEV})$

\footnotetext{
${ }^{8}$ The agricultural raw material index consists of timber, cotton, wool, rubber, and hides. The beverage index includes coffee, cocoa beans, and tea, while the metal index consists of copper, aluminum, iron ore, tin, nickel, zinc, lead, and uranium.

${ }^{9}$ In subsection 4.7 , we replace some of US variables by the global ones and examine the excess comovement by filtering out the global macroeconomic shocks.

${ }^{10} \mathrm{We}$ also confirm that residuals from the benchmark model (1) with $K=1$ are serially uncorrelated for all commodities.
} 
to 0.331 (OIL). Thus, some of comovement of commodity prices can be explained by common macroeconomic shocks.

To examine the excess comovement, we estimate the correlations among residuals from the benchmark model (1). Table 2 reports the estimated correlations and their standard errors. Four (AGR-MET, AGR-OIL, BEV-MET, and MET-OIL) out of six commodity pairs have a significant positive correlation at the $5 \%$ significance level, suggesting the existence of excess comovement of commodity prices. Although our significant correlations ranging from 0.116 to 0.199 are slightly lower than those of Pindyck and Rotemberg [23], which range from 0.118 to 0.281, our result of excess comovement is fairly consistent with theirs.

Deb, Trivedi, and Varangis [10] point out that the finding of excess comovement of commodity prices by Pindyck and Rotemberg [23] is sensitive to neglected conditional heteroskedasticity and time-varying conditional correlation in the commodity returns. Indeed, for the monthly data from 1960 to 1985 and from 1974 to 1992, they find weaker evidence of excess comovement especially when the multivariate GARCH model is applied. To examine the same possibility for the data through 2011, we estimate the DCC model (3) using the standardized residual $\hat{\boldsymbol{\varepsilon}}_{t}=\hat{\mathbf{D}}_{t}^{-1} \hat{\mathbf{u}}_{t}$ from the benchmark model (1) with a univariate GARCH model (2).

The estimated DCC parameters are $\hat{a}=0.004$ with a standard error of 0.013 and $\hat{b}=0.844$ with a standard error of 0.319 . Thus, although $a$ is not significant, $b$ is statistically significant, implying the importance of capturing the short-run fluctuation and serial correlation in conditional correlation. The estimated unconditional correlation of standardized disturbances is shown in Table 3. Three (AGR-OIL, BEV-MET, and MET-OIL) out of six commodity pairs show significant positive correlation, suggesting that evidence of excess comovement becomes weaker once we control the conditional heteroskedasticity and time-varying conditional correlation. The result is also arguably consistent with that of Deb, Trivedi, and Varangis [10].

Although we do not report them here, the time-series of conditional correlations between all commodity-pairs are mostly stable at the low level with no increasing trends. No increasing trend is similar to the results by Chong and Miffre [9], who find decreasing trends and Büyükşahin, Haigh, and Robe [5], who find no increasing trends of conditional correlations between stocks and commodities. ${ }^{11}$ Note, however, that it may be difficult to detect the trends in the time-series of conditional correlations estimated by the DCC model, since it assumes no trend in correlation. The following subsection shows this point.

\footnotetext{
${ }^{11}$ The time-series of conditional correlations exhibit much larger variation in Chong and Miffre [9] and Büyükşahin, Haigh, and Robe [5] most likely because they use weekly futures data.
} 


\subsection{Increasing trends in the excess comovement}

One restriction of the DCC models is that the unconditional correlation, or the stationary level of correlation, is constant, although the conditional correlation is time-varying. The recent growth of commodity index investment, however, might affect the stationary level of correlation gradually as the index investment grows. To investigate this possibility, we estimate the STC model (4) using the standardized residual $\hat{\boldsymbol{\varepsilon}}_{t}$ from the benchmark model (1) with a univariate GARCH model (2).

Table 4 documents the estimated unconditional correlation of the standardized disturbance of each regime. As can be seen, there is only weak evidence of excess comovement in regime 1 with a significant positive correlation for two (AGR-OIL and BEV-MET) out of six pairs. In addition, even for these two pairs, the magnitude of excess comovement is small with a correlation of 0.126 (AGR-OIL) and 0.098 (BEV-MET).

In contrast, all pairs show significant excess comovement in regime 2 with a much larger correlation. Indeed, all correlations are estimated at more than 0.4 , suggesting that the excess comovement becomes much larger in more recent periods. To examine an increase in the excess comovement more formally, we test the null hypothesis of the equivalence of correlation across regimes. The Wald statistic and its $p$-value are reported in the last two rows in Table 4 . The results indicate that the null hypothesis is rejected for all pairs at least at the $10 \%$ significance level, meaning there has been an increase in the excess comovement in recent years. Note also that the results suggest the importance of considering a possible regime change in unconditional correlation, which neither the benchmark nor the DCC model can capture.

Since our analysis demonstrates a significant increase in excess comovement, it is instructive to see when and how the increase occurred based on the STC model. To this end, we plot the estimated time series of correlation from the STC model in Figure 1. As can be seen, until 2000 the correlation of each pair was almost constant and remained at low levels with an average correlation of 0.084 at the end of 1999 . Note that these results are consistent with that of Deb, Trivedi, and Varangis [10], who find that excess comovement among commodities is weak for data from 1974 to 1992 when the time-varying conditional correlation is considered. However, excess comovement has increased gradually since 2000 and reached more than 0.25 for all pairs with an average correlation of about 0.4 in July 2011.

These results are generally consistent with Tang and Xiong's [28] finding of increasing trends in correlations between oil and non-energy commodities from (exogenously chosen) 2004 and the regime change in increasing correlations between commodities and stocks (or bonds) from around 2000 detected by Silvennoinen and Thorp [26], although they do not analyze the excess comovement. Also, this result is consistent with Le Pen and Sev́i [20], who find small increase of excess 
comovement among commodities between 2000 and 2004 and large increase after 2008 based on the rolling window analysis.

In summary, our results indicate the importance of accommodating a regime change in unconditional correlation or stationary level of correlation. More importantly, we find only weak evidence of the excess comovement of commodity prices in the earlier regime, but clear evidence of a significant increase in the excess comovement in the more recent regime. More specifically, the excess comovement has increased gradually since 2000 and become important in recent years with an average correlation of about 0.4 in July 2011.

\subsection{Long-run trends vs short-run dynamics}

Although the STC model with time as a transition variable is suitable for capturing long-run trends in unconditional correlation, one might wonder whether our finding of increasing excess comovement is an artifact by neglecting the short-run fluctuation of conditional correlation. Therefore, accommodating the short-run behavior of the conditional correlation in the STC model is instructive. To this end, we estimate the STDCC model (6) to take both long- and short-run dynamics of correlation into consideration.

The estimation results indicate that the DCC parameters turn out to be insignificant with the estimates of $\hat{a}=0.017$ and $\hat{b}=0.000$. This is in great contrast to the results of the DCC model where $\hat{b}=0.844$ is highly significant, suggesting that it is relatively more important to capture the long-run trends in correlation than the short-run dynamics in conditional correlation for our sample. The estimation results for the unconditional correlation of each regime are reported in Table 5. As can be seen, the results are very similar to those of the STC model. In particular, the results show no significant excess comovement for all commodity pairs in regime 1, but in regime 2 all excess comovements are significant. In addition, the null hypothesis of the equivalence of correlation across regimes is rejected for all pairs with significant increases. The dynamics of correlation in Figure 2 are also similar to those in Figure 1, with relatively small short-run fluctuation in conditional correlation. These results are not surprising, given that the DCC parameters are insignificant. ${ }^{12}$

In sum, it is more important to capture the possible regime change in unconditional correlation than to accommodate the short-run fluctuation in conditional correlation at least to capture the recent increasing trends in the excess comovement of commodity prices. Thus, the STC model seems to be sufficient for characterizing the increasing excess comovement in commodity prices from 1983 to 2011 for our monthly data. For this reason, we will use the STC model in the following analysis.

\footnotetext{
${ }^{12}$ One possible reason for the small short-run fluctuation is that we use monthly spot data.
} 


\subsection{Financial crisis and monotonicity of trends}

One limitation of the STC model with a time trend as a transition variable is that our model allows only the monotonic transition from the initial stationary correlation level $\mathbf{R}^{(1)}$ to the terminal stationary correlation level $\mathbf{R}^{(2)}$. However, the correlations among commodity returns may change non-monotonically over time. For example, Büyükşahin, Haigh, and Robe [5] find that the correlation between stock and commodity returns is positive and become much larger during the financial crisis, especially in the autumn of 2008, than in the preceding period. Thus, the return correlation may peak in the middle of the financial crisis after the bankruptcy of Lehman Brothers in September 2008 and become lower afterwards. If this is the case, the STC model could exaggerate the increase in excess comovement.

To examine this possibility, we develop the three-state STC model in which the time-varying correlation $\mathbf{R}_{t}$ is modeled as

$$
\mathbf{R}_{t}=\mathbf{R}^{(1)}+G_{1}\left(s_{t} ; c_{1}, \gamma_{1}\right)\left(\mathbf{R}^{(2)}-\mathbf{R}^{(1)}\right)+G_{2}\left(s_{t} ; c_{2}, \gamma_{2}\right)\left(\mathbf{R}^{(3)}-\mathbf{R}^{(2)}\right),
$$

where $G_{1}$ and $G_{2}$ are a logistic transition function with different location and smoothness parameters. We assume $0.01 \leq c_{1}<c_{2} \leq 0.99$ so that we can detect the correlation transition within the sample period. Under this assumption, time-varying correlation $\mathbf{R}_{t}$ changes smoothly through three stationary levels from $\mathbf{R}^{(1)}$ via $\mathbf{R}^{(2)}$ to $\mathbf{R}^{(3)}$ over time, as first the function $G_{1}$ changes from 0 to 1 , followed by a similar change in $G_{2}$. As a consequence, depending on the estimated values of $\mathbf{R}^{(1)}, \mathbf{R}^{(2)}$, and $\mathbf{R}^{(3)}$, we can detect non-monotonic as well as monotonic trends of excess comovement of commodity prices solely from the data. Note that Tang and Xiong [28] investigate only monotonic trends after 2004 and that Silvennoinen and Thorp [26], while allowing non-monotonic trends in their DSTCC-GARCH model, use the data up to July 2009. ${ }^{13}$

In Figure 3 the estimated correlation dynamics from the three-state STC model is plotted. The correlation dynamics is quite similar to that of the two-state STC model. Four pairs (AGR-MET, AGR-OIL, BEV-OIL, and MET-OIL) out of six show a monotonic increase in correlation with almost the same dynamics as that of the two-state model. Although the other two pairs (AGR$\mathrm{BEV}$ and BEC-MET) have some decrease in correlation in one regime, the magnitude of the decrease is smaller compared with the increase in the other regime. In addition, the log-likelihood of the three-state model (-1906.21) indicates a marginal increase from that of the two-state model (-1909.49). Indeed, usual information criteria such as the Akaike information criterion (AIC) support the two-state model over the three-state one. That is, the two-state model that captures

\footnotetext{
${ }^{13}$ The DSTCC-GARCH model with time for both transition variables can describe non-monotonic trends. Silvennoinen and Thorp [26] find this specification fits well for several commodities.
} 
only monotonic trends in correlation is enough to describe the dynamics of the excess comovement of commodity prices over the period from 1983 to 2011.

In sum, the results of the three-state model demonstrate that our finding of increasing trends in commodity excess comovement is not an artifact by the financial crisis after the bankruptcy of Lehman Brothers in September 2008, but the intrinsic nature of commodity excess comovement in the recent period.

\subsection{Change of sensitivities to common macroeconomic variables}

In our STC model, the sensitivities of commodity returns to common macroeconomic variables are assumed to be constant. In reality, there may be changes in the sensitivities over time. One may thus wonder whether our findings are due to ignorance of the changes in sensitivities to common macroeconomic factors. To explore this possibility, we develop the following smooth transition regression (STR) model:

$$
\begin{aligned}
\Delta p_{i t}=(1- & \left.G\left(s_{t} ; c_{m}, \gamma_{m}\right)\right)\left(\alpha_{i}^{(1)} \Delta x_{t}+\rho_{i}^{(1)} \Delta p_{i, t-1}+\sigma^{(1)} \varepsilon_{i t}\right) \\
& +G\left(s_{t} ; c_{m}, \gamma_{m}\right)\left(\alpha_{i}^{(2)} \Delta x_{t}+\rho_{i}^{(2)} \Delta p_{i, t-1}+\sigma^{(2)} \varepsilon_{i t}\right), \quad i=1, \ldots, M, t=1, \ldots, T .
\end{aligned}
$$

where $\varepsilon_{i t}$ is a standardized disturbance of commodity $i$. Thus, in the STR model, the coefficients of the macroeconomic variables can change, following a smooth transition model. We use the logistic transition function (5) and the time trend as a transition variable, as before. In addition, we allow the volatility to change, following the same smooth transitions to capture possible regime changes in volatility. We estimate the STR model (9) via MLE assuming $\varepsilon_{i t} \sim$ iid $N(0,1)$ to get the standardized residuals $\hat{\varepsilon}_{i t} .{ }^{14}$ Then, we estimate the STC model (4) using the standardized residual from the STR model assuming $\varepsilon=\left(\varepsilon_{1 t}, \ldots, \varepsilon_{M t}\right)^{\prime} \sim N\left(0, \mathbf{R}_{t}\right)$.

The estimation results of correlation of each regime for the standardized disturbance from the STR model are documented in Table 6. The results are qualitatively similar to those of the STC model. In particular, the results show no significant excess comovement for all commodity pairs in regime 1 , but in regime 2 , all excess comovements are significant with significant increases. Although the correlation dynamics plotted in Figure 4 become more linear than those in Figure 1, the increasing trends are still quite similar. Those results clearly indicate that our finding of increasing trends in excess comovement is not due to ignorance of changes in the effects of common macroeconomic variables.

\footnotetext{
${ }^{14}$ To save space, the estimation results of the STR model are not reported, but are available from the authors upon request.
} 


\subsection{Off-index commodities}

Our finding of increasing trends in the excess comovement of commodity prices is generally consistent with the increase in correlation between non-energy commodities and oil demonstrated by Tang and Xiong [28]. However, they also show that the increase in average correlation after 2004 is much larger among indexed commodities that are the components of either the S\&P-GSCI or DJUBS than among off-index commodities that are not components of the S\&P-GSCI or DJUBS. Thus, their results strongly suggest that the financialization of commodities through index investment starting around 2000 contributes to the increase in correlation. We thus investigate whether we find a similar difference for the excess comovement among off-index commodities.

The IMF commodity price indexes used for our analysis contain several off-index commodities as components. ${ }^{15}$ To examine the dynamics of excess comovement for these off-index commodities, we estimate the two-state STC model using the price data of hides (HID), softwood (SOF), tea (TEA), and tin (TIN). ${ }^{16}$

Table 7 reports the estimated unconditional correlation of standard residuals of each regime for off-index commodities. There is only weak evidence of excess comovement in regime 1 with a significant positive correlation only for the SOF-TIN pair. More importantly, the excess comovement of off-index commodity prices remains low in regime 2 with a significant positive correlation only for the HID-TIN pair. In addition, the test of equality of correlation across regimes indicates that there is no evidence of an increase in excess comovement for five pairs out of six. Furthermore, although the HID-TIN pair has a significant increase in excess comovement, its correlation is still below 0.15. Additionally, we can see the mostly stable low excess comovement of off-index commodities from the estimated time series of correlation plotted in Figure 5.

These results for off-index commodities are in contrast to those for the original price index, and consistent with Tang and Xiong [28]. Although other factors such as illiquidity may affect the correlations among off-index commodities, the results are still consistent with the view that the financialization of commodities through index investment starting around 2000 is one of the main sources of increases in the commodity excess comovement. Specifically, the results are generally consistent with the theoretical prediction by Basak and Pavlova [3] that in the presence of index

\footnotetext{
${ }^{15}$ These include hides, timber (hardwood and softwood), wool (fine and coarse), rubber for the agricultural raw material index; tea for the beverage index; and iron ore, tin, and uranium for the metal index.

${ }^{16}$ Among off-index commodities, monthly data for iron ore are available only as of recently. In addition, uranium prices did not change often for the first several years of the sample. Therefore, we exclude iron ore and uranium from our analysis. We include tea and tin in our analysis, since they are the only components from the beverage and metal categories that can be used. We also choose hides and softwood, since they have greater weight than wool and rubber. However, our result here is qualitatively similar even if we use wool and rubber instead of hides or softwood.
} 
investing in commodities, correlation among indexed commodities becomes higher than among off-index ones.

\subsection{Effects of global macroeconomic variables}

Another possible explanation of the increasing trends in excess comovement of commodity prices could be a surge of global commodity demand since the early 2000. Since we only control the US macroeconomic variables, increasing trends in the excess comovement might reflect such growth of world economy. To examine this possibility, we obtain the CPB industrial production world production weights index, the IMF world CPI, and MSCI world index from the Bloomberg and estimate the two-state STC model, using these data instead of US industrial production, CPI, and stock index data. ${ }^{17}$

The estimation results of unconditional correlation of standard residuals of each regime are shown in Table 8. The evidence of increase in the excess comovement of commodity prices becomes weaker, but still remains after accounting for global macroeconomic shocks. For instance, although BEV-OIL pair no longer has significant positive correlation in regime 2, the rest of pairs still show a significant excess comovement in more recent years. In addition, the correlations in regime 2 become uniformly smaller compared with those of Table 4 based on the US economic data, suggesting the degree of increase in the excess comovement is smaller. Nonetheless, the results indicate that four pairs out of six have a significant increase in the excess comovement, as can also be seen from the estimated dynamics of correlation shown in Figure 6. Furthermore, the rest of two pairs without significant increase has maintained the relatively high excess comovement throughout the entire sample period.

In sum, the analysis with the global economic variables demonstrates that our finding of increasing trends in excess comovement of commodity returns cannot be attributed entirely to the recent growth of world economy.

\section{Conclusion}

We investigate whether and how excess comovement of commodity returns have changed over time. For this purpose, we generalize the model of excess comovement, originated by Pindyck and Rotemberg [23] and extended by Deb, Trivedi, and Varangis [10], to the STDCC model, which can capture long-run trends of excess comovement in addition to short-run fluctuation. Using monthly commodity-return data from 1983 to 2011, we find the clear increasing long-run trends in excess

\footnotetext{
${ }^{17}$ Since the world economic data are available only from 1991:1, the sample period of this exercise is from 1991:2 to 2011:7.
} 
comovement, while there are little short-run fluctuation. We also find that the long-run trends start increasing since around 2000 and accelerate afterwards.

We conduct several robustness checks and confirm that these increasing trends are not just due to the financial crisis after the bankruptcy of Lehman Brothers in September 2008, the changes in sensitivities to common macroeconomic shocks, or the recent growth of world economy. Moreover, we find no significant increasing trends in the excess comovements among off-index commodity prices, suggesting that the financialization of commodities through index investment starting around 2000 is one of the main sources of increases in the commodity excess comovement.

These results complement Tang and Xiong [28], who find increasing trends in correlations between crude oil and non-energy commodities since 2004 and higher correlation among indexed commodities than among non-index ones, Silvennoinen and Thorp [26], who find a regime change in increasing correlations between commodities and stocks (or bonds) since around 2000, and Le Pen and Sev́i [20], who find small increase of excess comovement among commodities between 2000 and 2004 and large increase after 2008. These results are also consistent with the theoretical prediction of Basak and Pavlova [3], who show that in the presence of index investment into commodities, correlation among commodity returns increases and correlation among indexed commodities becomes higher than that among off-index ones. Our findings provide additional evidence for the timing and scope of the increasing commodity-return correlations in the recent period.

There remain several issues worth investigating. First, while we find that the short-run fluctuations in the excess comovements are much smaller than the long-run trends for monthly data, this may be due to our use of monthly spot data of commodity returns. It is, therefore, instructive to see whether we obtain similar results for weekly/daily futures returns. Second, to avoid somewhat arbitrary choice of macroeconomic variables that set "fundamentals," it is worth applying the large approximation factor model used by Le Pen and Sev́i [20] to extract the fundamental factors from a larger set of variables and analyzing the trends in the excess comovements. Third, it is interesting to investigate the cause of increasing excess comovement of commodity returns in more detail. It might be inventory, a flow of funds through index-investing (Tang and Xiong [28]; Silvennoinen and Thorp [26]), speculative activity of traders (Büyükşahin and Robe [6]; Le Pen and Sev́i [20]), supply factors based on inventory and harvest (Ai, Chatrath, and Song [2]), and so on. As already mentioned, however, such cause should generate the change of excess comovement with the timing and speed detected in this paper. Finally, recent empirical studies find that changes of commodity open interests predict asset returns (Etula [14]; Hong and Yogo [17]). It is intriguing to see how the results of this paper on commodity excess comovement may change if we include those variables in addition to macroeconomic control variables. These are issues left for future research. 


\section{Acknowledgements}

This study is conducted as a part of the Project "Exports and the Japanese Economy: Experiences in the 2000s and the lessons for the future" undertaken at Research Institute of Economy, Trade and Industry (RIETI). We are grateful to the anonymous referees for their helpful suggestions and comments. We are also indebted to Selma Chaker, Mardi Dungey, Evan Gatev, Jim Hamilton, Fumio Hayashi, Toshiki Honda, Akitoshi Ito, Takashi Kanamura, Hidetoshi Nakagawa, Katsushi Nakajima, Nobuhiro Nakamuara, Kiyotaka Satoyoshi, and seminar participants at RIETI, Hitotsubashi University, University of Tokyo, Kobe University, Yokohama National University, Australian National University, Monash University, University of Tasmania, Bank of Japan, Development Bank of Japan, Reserve Bank of New Zealand, International Conference on High-Frequency Data Analysis in Financial Markets, and Workshop on Financial Engineering and Financial Econometrics, International Conference on Frontiers in Macroeconometrics, 2013 NFA Annual Meeting, 2014 FMA Asian Conference, 2014 AsianFA Annual Meeting, ESAM/ACE 2014, and Conference on Recent Developments in Financial Econometrics and Applications. The first author thanks the Grant-in-Aid for Scientific Research for the financial support. The second author thanks the financial support by a grant-in-aid from Zengin Foundation for Studies on Economics and Finance.

\section{References}

[1] Adams, Z. and Glück, T., 2015. Financialization in commodity markets: A passing trend or the new normal?, Journal of Banking \& Finance 60, 93-111.

[2] Ai, C., Chatrath, A. and Song, F. 2006. On the Comovement of Commodity Prices, American Journal of Agricultural Economics 88(3), 574-588.

[3] Basak, S. and Pavlova, A., 2013. A Model of financialization of Commodities, forthcoming in Journal of Finance.

[4] Berben, R.-P. and Jansen, W.J., 2005. Comovement in international equity markets: A sectoral view. Journal of International Money and Finance 24, 832-857.

[5] Büyükşahin, B, Haigh, M. S., and Robe, M. A., 2010. Commodities and equities: Ever a "market of one"? Journal of Alternative Investments 12, 76-95. 
[6] Büyükşahin, B. and Robe, M. A., 2014. Speculators, commodities and cross-market linkages, Journal of International Money and Finance 42, 38-70.

[7] Cashin, P., McDermott, C. J., and Scott, A., 1999. The myth of co-moving commodity prices. Reserve Bank of New Zealand, G99/9.

[8] Cheng, I-H. and Xiong W., 2014, Financialization of Commodity Markets, Annual Review of Financial Economics 6, 419-441.

[9] Chong, J. and Miffre, J., 2010. Conditional correlation and volatility in commodity futures and traditional asset markets. Journal of Alternative Investments 12, 61-75.

[10] Deb, P., Trivedi, P.K. and Varangis, P., 1996. The excess comovement of commodity prices reconsidered. Journal of Applied Econometrics 11(3), 275-291.

[11] Engle, R.F., 2002. Dynamic conditional correlation: A simple class of multivariate generalized autoregressive conditional heteroskedasticity models. Journal of Business and Economic Statistics 20(3), 339-350.

[12] Engle, R.F. and Kroner, K.F., 1995. Multivariate simultaneous generalized ARCH. Econometric Theory 11, 122-150.

[13] Erb, C.B. and Harvey, C.R., 2006. The strategic and tactical value of commodity futures. Financial Analysts Journal 62, 69-97.

[14] Etula, E., 2013. Broker-dealer risk appetite and commodity returns. Journal of Financial Econometrics 11, 486-521.

[15] Gorton, G.B. and Rouwenhorst, G.K., 2006. Facts and fantasies about commodity futures. Financial Analysts Journal 62, 47-68.

[16] Greer, R., 2000. The nature of commodity index returns. Journal of Alternative Investments $3,45-53$.

[17] Hong, H. and Yogo, M., 2012. What does futures market interest tell us about the macroeconomy and asset prices? Journal of Financial Economics 105, 473-490.

[18] Irwin, S. H. and Sanders D. R., 2012. Testing the Masters Hypothesis in commodity futures markets. Energy Economics 34, 256-69. 
[19] Kumar, M.S. and Okimoto, T., 2011. Dynamics of international integration of government securities' markets. Journal of Banking and Finance 35, 142-154.

[20] Le Pen, Y. and Sev́i, B., 2013. Futures trading and the excess comovement of commodity prices, SSRN: http://ssrn.com/abstract=2191659

[21] Lin, C.-F.J. and Teräsvirta, T., 1994. Testing the constancy of regression parameters against continuous structural change. Journal of Econometrics 62, 211-228.

[22] Palaskas, T. B. and Varangis, P. N., 1991. Is there excess co-movement of primary commodity prices?: A co-integration test. Working Paper Series No. 758, International Economics Department, Washington D.C.: World Bank.

[23] Pindyck, R.S. and Rotemberg, J.J., 1990. The excess co-movement of commodity prices. Economic Journal 100, 1173-1187.

[24] Pradhananga, M. 2015. Financialization and the rise in comovement of commodity prices. PERI Working Paper 378, University of Massachusetts Amherst.

[25] Silvennoinen, A. and Teräsvirta, T., 2015. Modeling conditional correlations of asset returns: A smooth transition approach, Econometric Review 34, 174-197.

[26] Silvennoinen, A. and Thorp, S., 2013. Financialization, crisis and commodity correlation dynamics. Journal of International Financial Markets, Institutions and Money 24, 42-65.

[27] Stoll, H and Whaley R., 2010. Commodity index investing and commodity futures prices, Journal of Applied Finance 20, 1-40.

[28] Tang, K. and Xiong, W., 2012. Index investment and the financialization of commodities, Financial Analysts Journal 68, 54-74.

[29] Teräsvirta, T., 1994. Specification, estimation, and evaluation of smooth transition autoregressive models, Journal of the American Statistical Association 89(425), 208-218. 
Table 1: Estimation results of the benchmark model

\begin{tabular}{|c|c|c|c|c|c|c|c|c|}
\hline & \multicolumn{2}{|c|}{ Agriculture } & \multicolumn{2}{|c|}{ Beverage } & \multicolumn{2}{|c|}{ Metal } & \multicolumn{2}{|c|}{ Oil } \\
\hline & Estimate & $\begin{array}{l}\text { Std. } \\
\text { Error }\end{array}$ & Estimate & $\begin{array}{l}\text { Std. } \\
\text { Error }\end{array}$ & Estimate & $\begin{array}{l}\text { Std. } \\
\text { Error }\end{array}$ & Estimate & $\begin{array}{l}\text { Std. } \\
\text { Error }\end{array}$ \\
\hline$\Pi$ & $1.7580^{* *}$ & 0.7394 & 1.1726 & 1.1430 & 1.6743 & 1.0163 & $15.0280 * * *$ & 1.8339 \\
\hline$\Pi(-1)$ & 0.6650 & 0.7564 & -0.6274 & 1.1761 & $-1.8244^{*}$ & 1.0393 & $-8.0614^{* * *}$ & 1.7882 \\
\hline $\mathrm{Y}$ & $0.5186^{*}$ & 0.2790 & 0.5465 & 0.4313 & $0.9371^{* *}$ & 0.3820 & 0.8236 & 0.6564 \\
\hline $\mathrm{Y}(-1)$ & 0.3431 & 0.2809 & 0.2598 & 0.4338 & 0.4803 & 0.3852 & $1.1411^{*}$ & 0.6629 \\
\hline $\mathrm{R}$ & 0.0118 & 0.0086 & $0.0251^{*}$ & 0.0133 & $0.0249 * *$ & 0.0118 & $0.0448^{* *}$ & 0.0204 \\
\hline $\mathrm{R}(-1)$ & 0.0025 & 0.0087 & -0.0003 & 0.0133 & 0.0062 & 0.0119 & -0.0087 & 0.0205 \\
\hline $\mathrm{E}$ & $-0.2144^{* *}$ & 0.1065 & $-0.4199^{* *}$ & 0.1641 & $-0.8472^{* * *}$ & 0.1466 & $-0.6384^{* *}$ & 0.2515 \\
\hline $\mathrm{E}(-1)$ & 0.0857 & 0.1064 & -0.0505 & 0.1644 & -0.0913 & 0.1460 & -0.3575 & 0.2514 \\
\hline M & -0.2405 & 0.2264 & 0.2985 & 0.3525 & -0.1414 & 0.3104 & $-1.1522^{* *}$ & 0.5343 \\
\hline $\mathrm{M}(-1)$ & 0.1147 & 0.2225 & -0.3312 & 0.3460 & -0.2577 & 0.3055 & -0.3350 & 0.5258 \\
\hline $\mathrm{S}$ & 0.0050 & 0.0380 & -0.0791 & 0.0585 & 0.0040 & 0.0523 & -0.1069 & 0.0899 \\
\hline $\mathrm{S}(-1)$ & 0.0539 & 0.0383 & 0.0348 & 0.0590 & $0.1814^{* * *}$ & 0.0526 & -0.1449 & 0.0907 \\
\hline AR1 & $0.1685^{* * *}$ & 0.0550 & $0.2898^{* * *}$ & 0.0533 & $0.1859 * * *$ & 0.0548 & $0.1836^{* *}$ & 0.0576 \\
\hline $\mathrm{R}^{2}$ & 0.1446 & & 0.1423 & & 0.2442 & & 0.3309 & \\
\hline
\end{tabular}

Note: Table 1 reports the estimation results of the benchmark model (1), for the agricultural raw material (AGR), beverage (BEV), and metal (MET) price indices and the average oil prices (OIL). The common macroeconomic variables include the seasonally adjusted consumer price index (CPI, $\Pi$ ), the seasonally adjusted industrial production (Y), the 3-month Treasury bill rate $(R)$, the trade weighted exchange rate index (E), the seasonally adjusted money supply, M1 (M), and the $\mathrm{S} \& \mathrm{P} 500$ stock price index $(\mathrm{S}) . * / * * / * * *$ indicates that the variable is significant at the $10 \% / 5 \% / 1 \%$ level of significance, respectively. 
Table 2: Estimation results of excess comovement for the benchmark model

\begin{tabular}{|c|c|c|c|c|c|c|}
\hline & AGR-BEV & AGR-MET & AGR-OIL & BEV-MET & BEV-OIL & MET-OIL \\
\hline Estimate & 0.0493 & $0.1159^{* *}$ & $0.1933^{* * *}$ & $0.1316^{* *}$ & 0.0110 & $0.1992^{* * *}$ \\
\hline Std. Error & 0.0542 & 0.0539 & 0.0533 & 0.0538 & 0.0543 & 0.0532 \\
\hline
\end{tabular}

Note: Table 2 documents the correlations among residuals from the benchmark model (1). Each row reports the estimated correlation and its standard error for each commodity pair. */**/*** indicates that the variable is significant at the $10 \% / 5 \% / 1 \%$ level of significance, respectively. 
Table 3: Estimation results of excess comovement for the DCC model

\begin{tabular}{|c|c|c|c|c|c|c|}
\hline & AGR-BEV & AGR-MET & AGR-OIL & BEV-MET & BEV-OIL & MET-OIL \\
\hline Estimate & 0.0663 & 0.0941 & $0.2134^{* * *}$ & $0.1343^{* * *}$ & 0.0049 & $0.1600^{* * *}$ \\
\hline Std. Error & 0.0631 & 0.0599 & 0.0544 & 0.0587 & 0.0608 & 0.0560 \\
\hline
\end{tabular}

Note: Table 3 reports the estimation results of excess comovement for the DCC model (3). Each row reports the estimated correlation and its standard error for each commodity pair. */**/*** indicates that the variable is significant at the $10 \% / 5 \% / 1 \%$ level of significance, respectively. 
Table 4: Estimation results of excess comovement for the STC model

\begin{tabular}{|c|c|c|c|c|c|c|c|}
\hline \multicolumn{2}{|l|}{} & AGR-BEV & AGR-MET & AGR-OIL & BEV-MET & BEV-OIL & MET-OIL \\
\hline Regime 1 & Estimate & 0.0334 & 0.0204 & $0.1261^{* * *}$ & $0.0978^{* *}$ & -0.0427 & 0.0756 \\
\hline \multirow{2}{*}{ Regime 2 } & Estimate & $0.4372^{* * *}$ & $0.7462^{* * * *}$ & $0.9647^{* * *}$ & $0.4800^{* * *}$ & $0.5176^{* * *}$ & $0.8931^{* * * *}$ \\
\hline & Std. Error & 0.0484 & 0.0511 & 0.0340 & 0.0494 & 0.0458 & 0.0546 \\
\hline \multirow{2}{*}{$\begin{array}{c}\text { Test of } \\
\text { equality }\end{array}$} & Wald stat & 3.4396 & 51.8552 & 27.3220 & 12.9783 & 19.4645 & 27.5511 \\
\cline { 2 - 9 } & P-value & 0.0637 & 0.0000 & 0.0000 & 0.0003 & 0.0000 & 0.0000 \\
\hline
\end{tabular}

Note: Table 4 reports the estimation results of excess comovement for the STC model (4) with $s_{t}=t / T$, where $T$ is the sample size. The second and third row show the estimated correlation and its standard error for Regime 1 for each commodity pair, while the fourth and fifth rows report the estimated correlation and its standard error for Regime 2 . The last two rows document the Wald statistic and its p-value to test the null hypothesis of the equivalence of correlation across regimes. $* / * * / * * *$ indicates that the variable is significant at the $10 \% / 5 \% / 1 \%$ level of significance, respectively. 
Table 5: Estimation results of excess comovement for the STDCC model

\begin{tabular}{|c|c|c|c|c|c|c|c|}
\hline \multicolumn{2}{|l|}{} & AGR-BEV & AGR-MET & AGR-OIL & BEV-MET & BEV-OIL & MET-OIL \\
\hline \multirow{2}{*}{ Regime 1 } & Estimate & 0.0309 & 0.0286 & 0.1116 & 0.1004 & -0.0388 & 0.0741 \\
\hline \multirow{2}{*}{ Regime 2 } & Estimate & $0.4157^{* * *}$ & $0.6722^{* * *}$ & $0.9732^{* * *}$ & $0.3992^{* * *}$ & $0.4415^{* * * *}$ & $0.8245^{* * *}$ \\
\hline & Std. Error & 0.1362 & 0.1864 & 0.3901 & 0.1502 & 0.1017 & 0.3488 \\
\hline \multirow{2}{*}{$\begin{array}{c}\text { Test of } \\
\text { equality }\end{array}$} & Wald stat & 2.9897 & 6.2469 & 4.2997 & 2.7483 & 7.9954 & 2.8039 \\
\cline { 2 - 9 } & P-value & 0.0838 & 0.0124 & 0.0381 & 0.0974 & 0.0047 & 0.0940 \\
\hline
\end{tabular}

Note: Table 5 reports the estimation results of excess comovement for the STDCC model (6) with $s_{t}=t / T$, where $T$ is the sample size. The second and third rows show the estimated correlation and its standard error for Regime 1 for each commodity pair, while the fourth and fifth rows report the estimated correlation and its standard error for Regime 2 . The last two rows document the Wald statistic and its p-value to test the null hypothesis of the equivalence of correlation across regimes. $* / * * / * * *$ indicates that the variable is significant at the $10 \% / 5 \% / 1 \%$ level of significance, respectively. 
Table 6: Estimation results of excess comovement for the residuals from the STR model

\begin{tabular}{|c|c|c|c|c|c|c|c|}
\hline \multicolumn{2}{|l|}{} & AGR-BEV & AGR-MET & AGR-OIL & BEV-MET & BEV-OIL & MET-OIL \\
\hline \multirow{2}{*}{ Regime 1 } & Estimate & -0.1023 & -0.0279 & -0.0144 & 0.0443 & -0.0882 & -0.0771 \\
\hline & Std. Error & 0.0691 & 0.0723 & 0.0906 & 0.0751 & 0.0816 & 0.1103 \\
\hline \multirow{2}{*}{$\begin{array}{c}\text { Regime 2 } \\
\text { Test of }\end{array}$} & Estimate & $0.4706^{* * *}$ & $0.6930^{* * *}$ & $0.8156^{* * *}$ & $0.3212^{* * *}$ & $0.4041^{* * *}$ & $0.9819^{* * *}$ \\
\cline { 2 - 9 } & Std. Error & 0.1190 & 0.1387 & 0.1966 & 0.1025 & 0.1162 & 0.2328 \\
\hline
\end{tabular}

Note: Table 6 reports the estimation results of excess comovement for the residuals from the STR model consisting of (8) and (4) with $s_{t}=t / T$, where $T$ is the sample size. The second and third rows show the estimated correlation and its standard error for Regime 1 for each commodity pair, while the fourth and fifth rows report the estimated correlation and its standard error for Regime 2. The last two rows document the Wald statistic and its p-value to test the null hypothesis of the equivalence of correlation across regimes. $* / * * / * * *$ indicates that the variable is significant at the $10 \% / 5 \% / 1 \%$ level of significance, respectively. 
Table 7: Estimation results of excess comovement for off-index commodities

\begin{tabular}{|c|c|c|c|c|c|c|c|}
\hline \multicolumn{2}{|l|}{} & HID-SOF & HID-TEA & HID-TIN & SOF-TEA & SOF-TIN & TEA-TIN \\
\hline \multirow{2}{*}{ Regime 1 } & Estimate & 0.1112 & 0.1021 & $-0.1401^{*}$ & -0.0234 & $0.1509^{*}$ & -0.0679 \\
\hline \multirow{2}{*}{ Regime 2 } & Estimate & 0.0027 & 0.0380 & $0.1398^{*}$ & -0.1052 & 0.0022 & -0.0331 \\
\hline \multirow{2}{*}{$\begin{array}{c}\text { Test of } \\
\text { equality }\end{array}$} & Std. Error & 0.0727 & 0.0758 & 0.0722 & 0.0710 & 0.0704 & 0.0733 \\
\cline { 2 - 9 } & P-value & 0.3212 & 0.5513 & 0.0086 & 0.4682 & 0.1717 & 0.7500 \\
\hline
\end{tabular}

Note: Table 7 reports the estimation results of excess comovement for the STC model (4) with $s_{t}=t / T$, where $T$ is the sample size, using the price data of hides (HID), softwood (SOF), tea (TEA), and tin (TIN). The second and third rows show the estimated correlation and its standard error for Regime 1 for each commodity pair, while the fourth and fifth rows report the estimated correlation and its standard error for Regime 2. The last two rows document the Wald statistic and its $\mathrm{p}$-value to test the null hypothesis of the equivalence of correlation across regimes. $* / * * / * * *$ indicates that the variable is significant at the $10 \% / 5 \% / 1 \%$ level of significance, respectively. 
Table 8: Estimation results of excess comovement based on global economic variables

\begin{tabular}{|c|c|c|c|c|c|c|c|}
\hline \multicolumn{2}{|l|}{} & AGR-BEV & AGR-MET & AGR-OIL & BEV-MET & BEV-OIL & MET-OIL \\
\hline Regime 1 & Estimate & -0.0850 & $-0.2388^{*}$ & $0.3925^{* * *}$ & 0.1570 & $-0.2177^{*}$ & -0.1031 \\
\hline & Std. Error & 0.1380 & 0.1402 & 0.1225 & 0.1122 & 0.1341 & 0.1558 \\
\hline Regime 2 & Estimate & $0.2315^{* * *}$ & $0.2416^{* * *}$ & $0.2515^{* * *}$ & $0.1487^{* *}$ & 0.0759 & $0.2373^{* * *}$ \\
\hline \multirow{2}{*}{$\begin{array}{c}\text { Test of } \\
\text { equality }\end{array}$} & Std. Error & 0.0822 & 0.0685 & 0.0662 & 0.0822 & 0.0776 & 0.0752 \\
\cline { 2 - 9 } & Pald stat & 3.3206 & 9.3030 & 0.9154 & 0.0030 & 3.1749 & 3.4070 \\
\hline
\end{tabular}

Note: Table 8 reports the estimation results of excess comovement for the STC model (4) with $s_{t}=t / T$, where $T$ is the sample size, using the world economic variables as control variables. The second and third rows show the estimated correlation and its standard error for Regime 1 for each commodity pair, while the fourth and fifth rows report the estimated correlation and its standard error for Regime 2. The last two rows document the Wald statistic and its p-value to test the null hypothesis of the equivalence of correlation across regimes. $* / * * / * * *$ indicates that the variable is significant at the $10 \% / 5 \% / 1 \%$ level of significance, respectively. 
Figure 1: Dynamics of excess comovement of commodity prices (STC model)

Figure 1 plots the dynamics of excess comovement of commodity prices for each commodity pair based on the STC model (4) with $s_{t}=t / T$, where $T$ is the sample size.
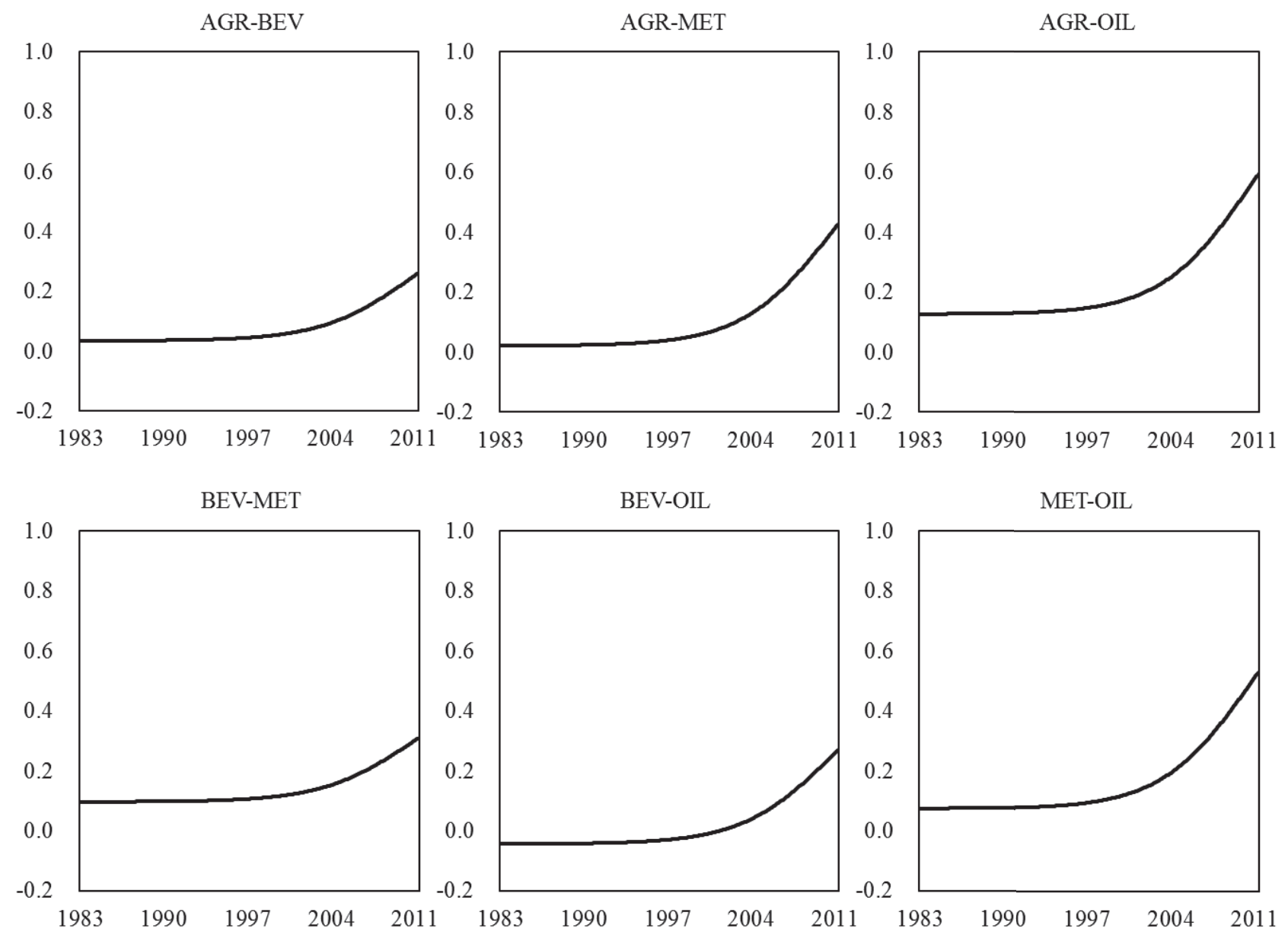
Figure 2: Dynamics of excess comovement of commodity prices (STDCC model)

Figure 2 plots the dynamics of excess comovement of commodity prices for each commodity pair based on the STDCC model (5) with $s_{t}=t / T$, where $T$ is the sample size.
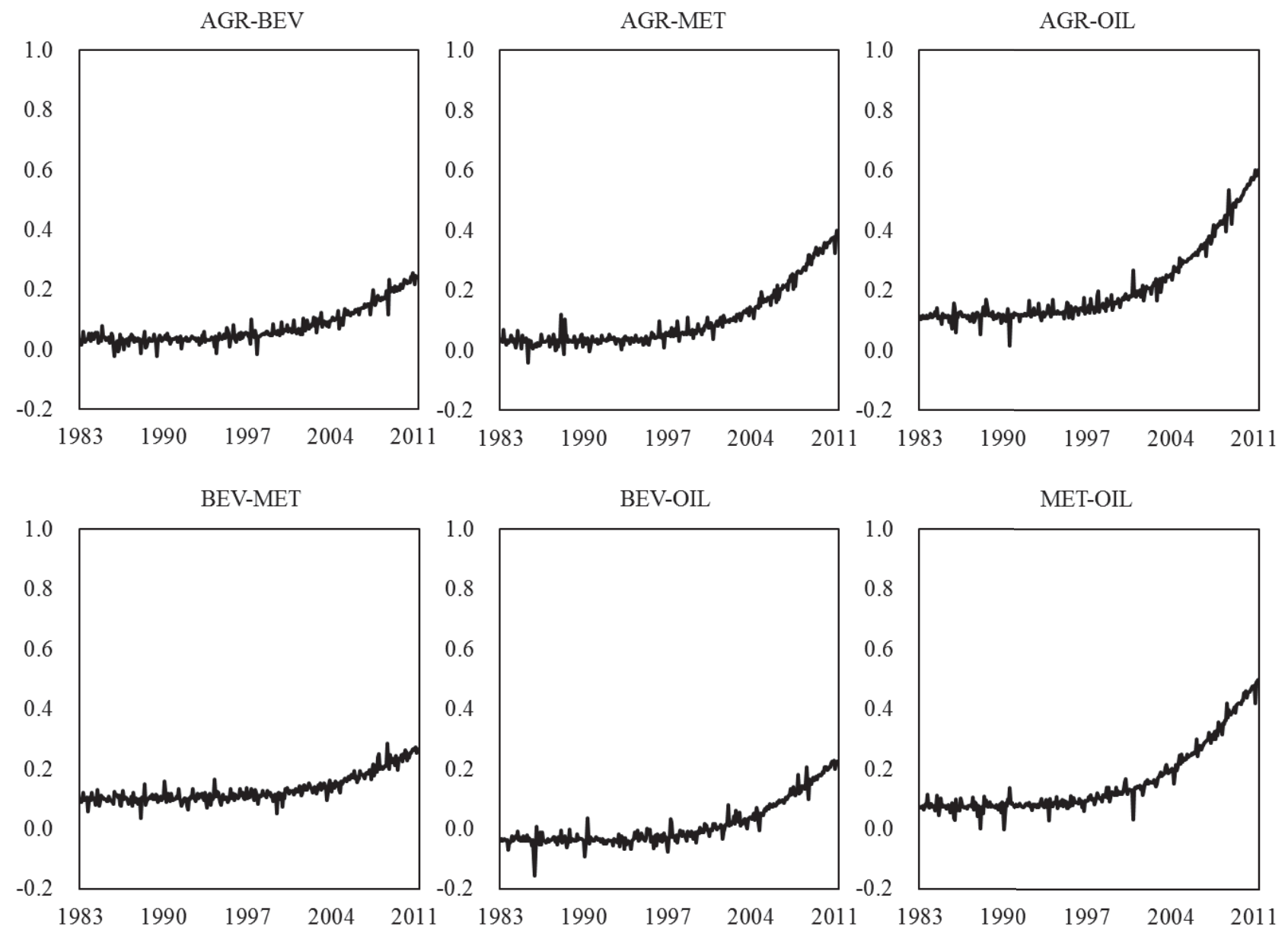
Figure 3: Dynamics of excess comovement of commodity prices (three-state STC model)

Figure 3 plots the dynamics of excess comovement of commodity prices for each commodity pair based on the three-state STC model (8) with $s_{t}=t / T$, where $T$ is the sample size.
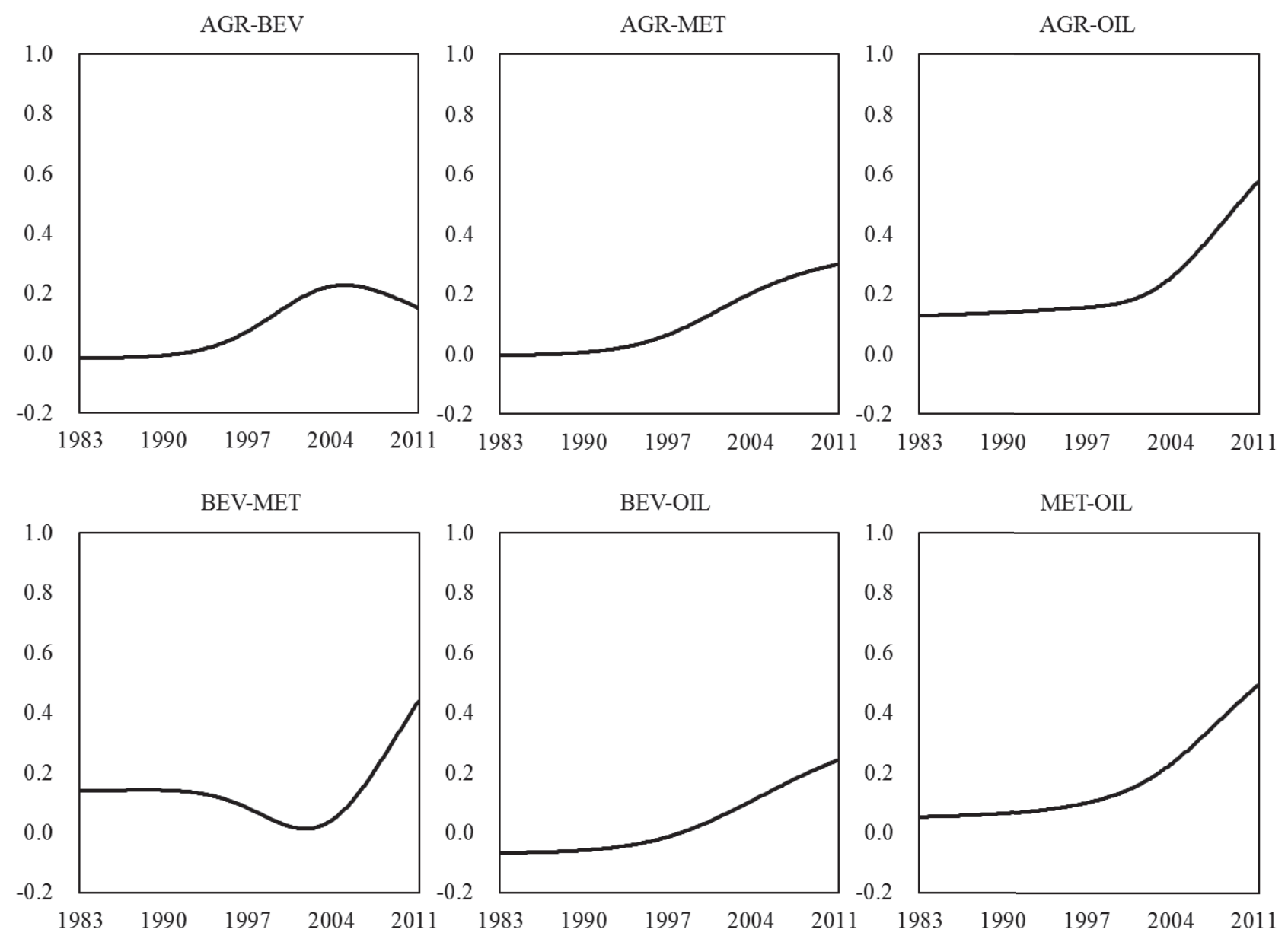
Figure 4: Dynamics of excess comovement of commodity prices (STR residuals)

Figure 4 plots the dynamics of excess comovement of commodity prices for each commodity pair based on the residuals from STR model consisting of (9) and (4) with $s_{t}=t / T$, where $T$ is the sample size..
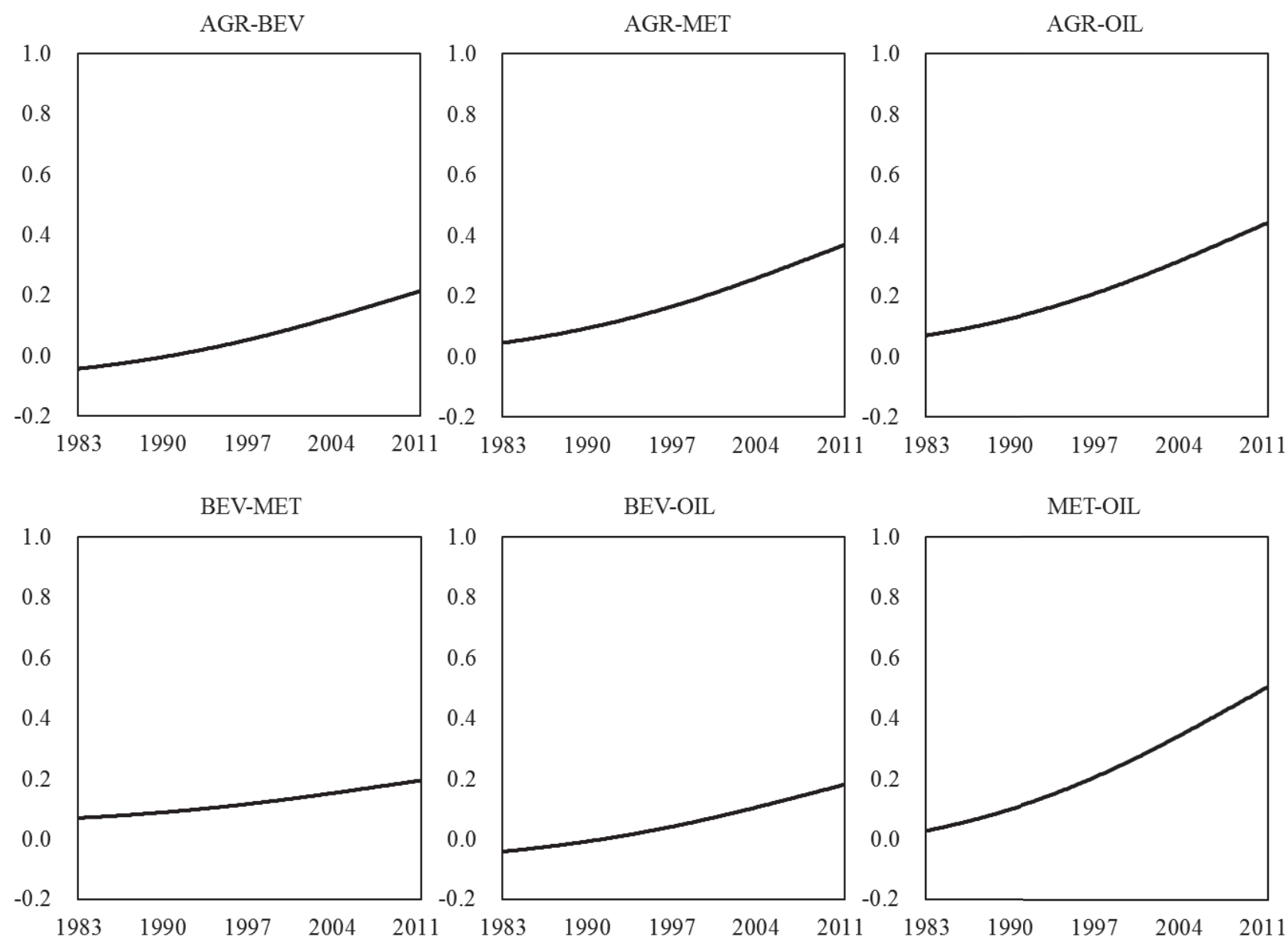
Figure 5: Dynamics of excess comovement of off-index commodity prices (STC model)

Figure 5 plots the dynamics of excess comovement of commodity prices based on the STC model (4) with $s_{t}=t / T$, where $T$ is the sample size, using the price data of hides (HID), softwood (SOF), tea (TEA), and tin (TIN).
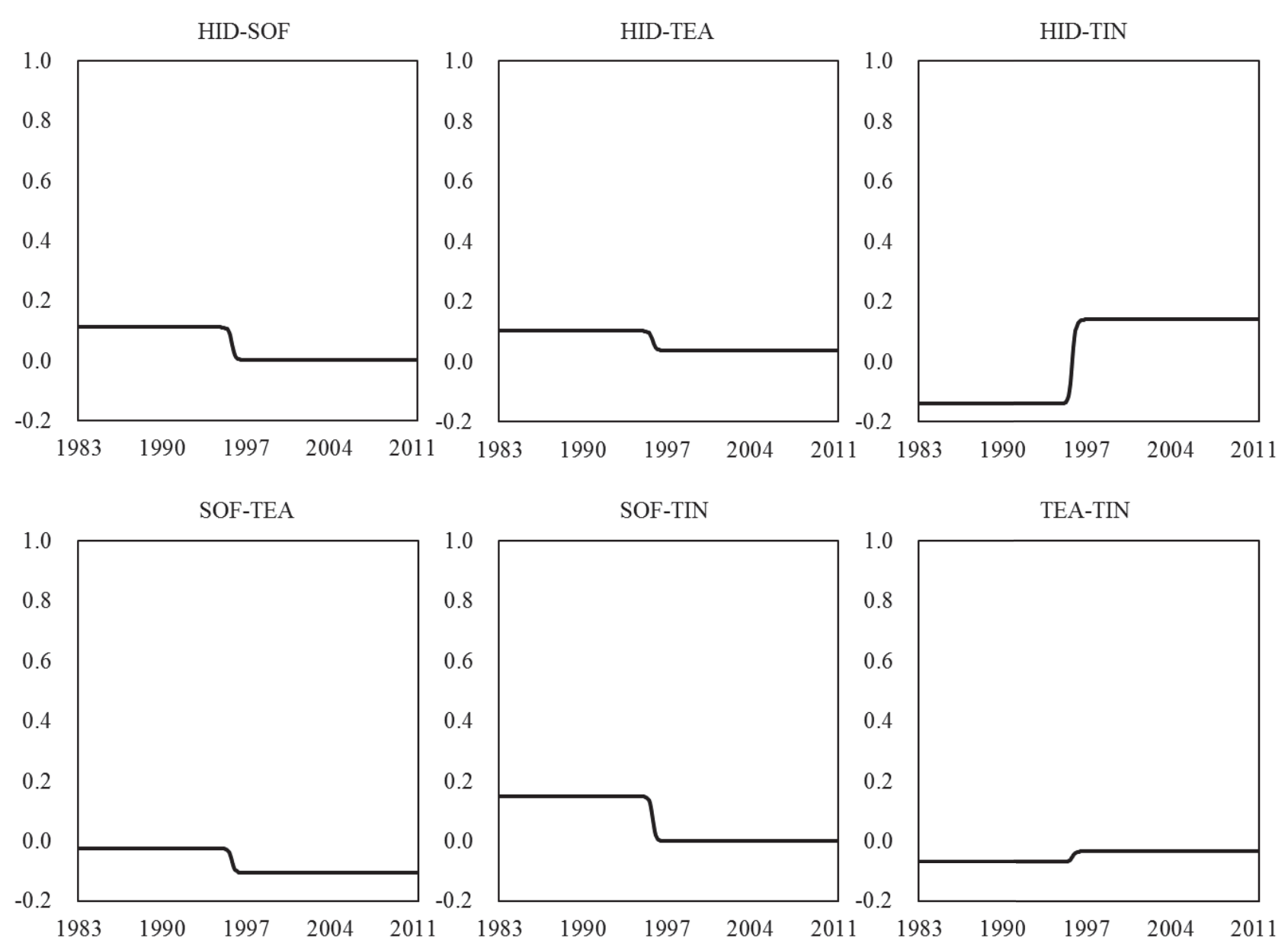
Figure 6: Dynamics of excess comovement of commodity prices (global economic variables)

Figure 6 plots the dynamics of excess comovement of commodity prices based on the STC model (4) with $s_{t}=t / T$, where $T$ is the sample size, using the world economic variables as part of control variables.
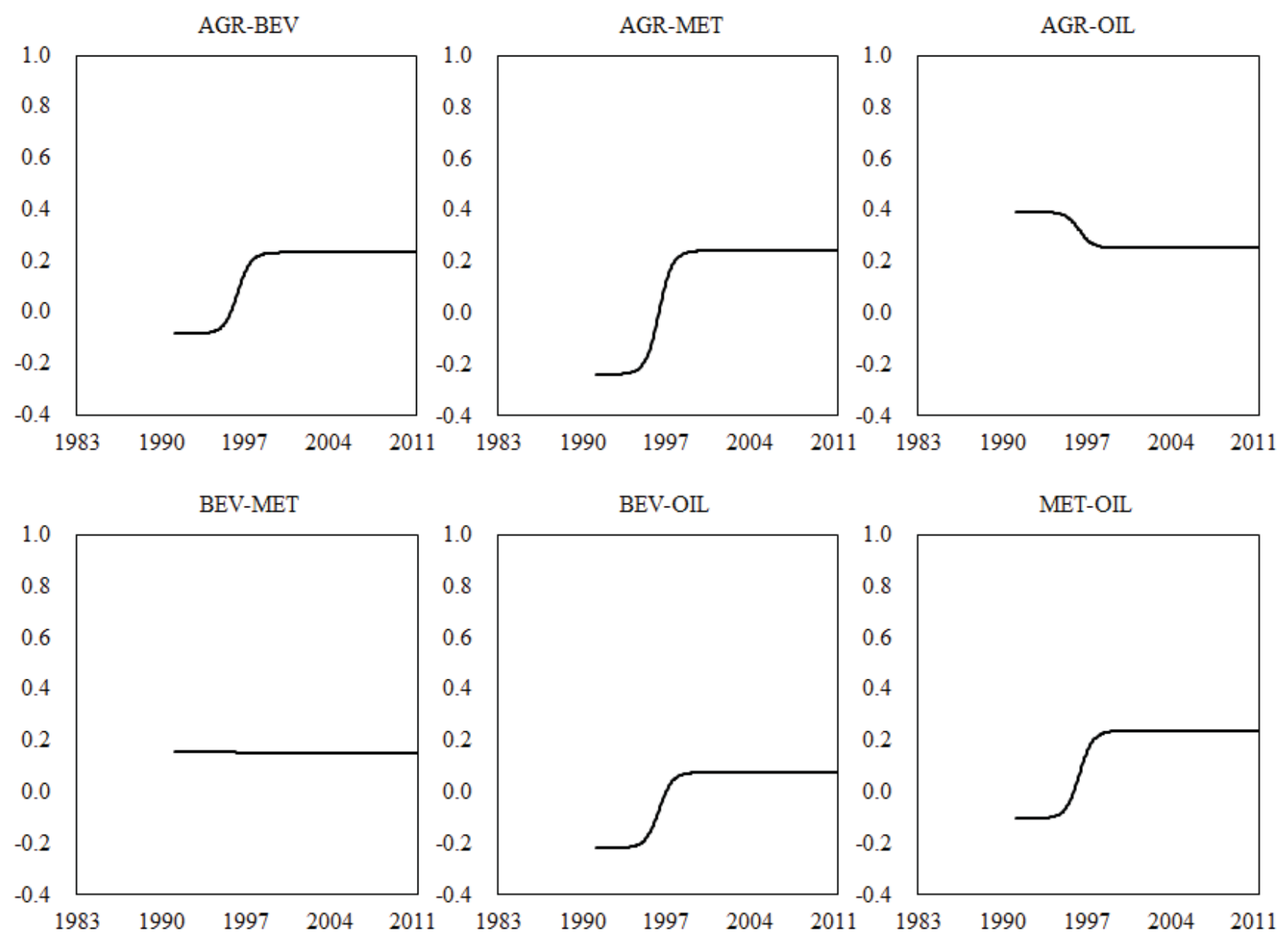